http://dx.doi.org/10.1590/0370-44672019740141

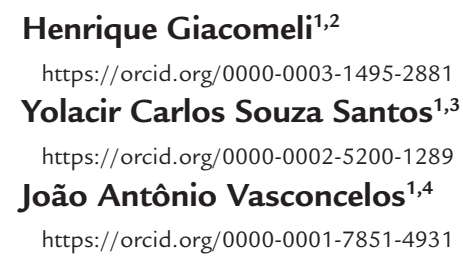

'Agência Nacional de Mineração - ANM, Vitória - Espírito Santo - Brasil.

E-mails: ${ }^{2}$ henrique.giacomeli@anm.gov.br, 3yolacir@yahoo.com.br,

vasconcelos_ufop@yahoo.com.br

\section{Technical dossier and legal proceedings in Brazilian dimension stone mining}

\begin{abstract}
This article presents a guide to be followed by mining companies willing to open a dimension stone quarry in Brazilian territory. It highlights the main technical documents required by Federal legislation to obtain mining authorization. These documents and their singularities were compiled based on a study of Brazilian mining laws, other normative instruments and scientific literature. The Brazilian mining law describes five Federal authorizations, in which two could be obtained for the dimension stone mining purpose: authorization/concession and licensing regimes. To obtainment the main mining permission may extend for many years. However, it is possible to acquire a kind of provisional permission in much less time, so that the quarry activities can begin before the acquisition of the main permission, which has no deadline. In general, the required technical mining dossier shows a wide range of information. For these reasons, one of the best ways to reduce the time spent through legal procedures is based upon paying special attention at the quality and level of proper instruction of the documents delivered to National Mining Agency (ANM). The author's experience reveals that knowledge of the technical documents provides legal safety for the company, in a context where the miner has to deal with economic, regulatory, environmental and occupational risks.
\end{abstract}

keywords: Dimension stones, technical documents, authorization, mining. 


\section{Introduction}

The Brazilian mining law in vigor since the time of the Brazilian Empire (the period between Brazilian Independence Day and the start of the Republican Regime, 07/09/1822 to 15/11/1889), has undergone significant changes. These changes are a result of the government's efforts to create a modern environment for the fomentation and development of mining, while providing greater legal, economic and occupational safety for this industry, which is crucial for the urban society development. As all mining activity, dimension stone miners target at raw material, and the companies engaged usually are of small business category, with no capital funded by the stock market. When considering these peculiarities, we can say that the dimension stones do not properly fit in the definition for commodity as other mineral resources do. Another interesting point of that segment is the fact that dimension stone quarries are essentially operated by medium to low sized companies. They are, frequently a family business type, with a low grade of specialized technical utilization at its mining operations. It is a situation different from the multinational corporations in metallic mining. Consequently, dimension stone miners are much more vulnerable to regulatory risks.

According to the Brazilian Constitution, article 20, item IX, the mineral resources in national territory, including those that are underground, belong to the Union. Then the exploration rights must be requested to the Federal Government, who has the power and duty to grant and regulate this kind of activity. The legal procedures for the issuing of such authorizations are managed by the National Mining Agency created by Federal Law $\mathrm{n}^{\circ} 13.575$ de 26/12/2017. This new regulatory agency replaces the Mineral Production National Department (DNPM), the oldest federal autarchy in Brazilian government, and since its creation, has been managing and regulating all mining activity inside Brazilian frontiers. The Geology and Mineral Transformation Secretariat, subordinate to the Energy and Mining Ministry, is an important participant in the management and regulation of the mining industry. Agra et al. (2011) show that the mining authorization acquisition is one of the main difficulties faced by the small-sized dimension stone business in Brazil. This article presents a discussion on the main technical documents needed to open a dimension stone quarry in Brazilian territory according to the Mining Code and complementary legislation. It is important to highlight that some aspects pointed out in the documental miscellany came from the authors' opinions built during years of experience working as federal agents in this mining segment, performing their roles in the Espírito Santo state, where the dimension stone industry has been quite relevant for at least half of a century at a national purview.

\section{Exploration and exploitation Regimes according to the Brazilian Mining Code}

The major law ruling all mining activities in Brazilian territory is the Decree-Law n²27/1967, also called the Mining Code. It represents an important update to the edition of the Federal mining law (Decree-Law n ${ }^{\circ} .985 / 1940$ ). The first one presents in its article $2^{\circ}$ the mining regimes, which are: concession, authorization, licensing, alluvial extraction permit and monopoly. Applied to dimension stone mining, according to current Brazilian legislation, authorization/concession could be utilized, due to the new modifications brought by Law 13.975/2020 which amends the Law $n^{\circ} 6567 / 1978$, licensing regime.
I - Concession Regime: this is the main regime for mine exploitation and is used for most mineral resources. It is represented by the mining permit, defined as a title that reveals the Energy and Mining Minister or Geology and Mineral Transformation Secretary consent for the mining operation required, whose authorization has no deadline. Recently with the ANM creation, mining permits for exploitation of mineral resources, for construction usage, are granted by ANM's General-Director.

II - Authorization Regime: in this regime the Federal Government authorizes the exploration activity through the granting of the Exploration Permit for 01 up to a 03-year deadline. Involving prospecting and researching for ore, the deposit quantification, and the economic value setting. Extracting operation in this phase is allowed only in situations defined by the mining law as "exceptionality"; this point will be discussed in-depth ahead.

III - licensing regime: it is a simplified procedure in which the miner is exempt from doing mineral exploration to get an exploitation permit. Through this regime, it is allowed areas up to 50 hectares. More details of this regime are discussed in 3.6 and 4 items ahead.

\section{Permit Requests and its technical documents}

\subsection{Exploration Permit Request (EPR)}

It's the first document to be generated by the miner to deliver to ANM, but before that, the company (or natural person) is obliged to sign up for the Mining Rights Ownership Database (CTDM), where their registration data must be informed.

After this, the applicant, together with its consultant, which in this particular case must be a geologist or mining engineer, needs to fill out the prospecting request form (template is available on the ANM website). In this request, the fol- lowing information must to be furnished: applicant name, representative, technician responsible, mineral substances targeted and their likely applicability, prospecting work budget, land properties, and specialties, if present, such as depth limit for depth requests. In addition, the EPR has to be presented with other documents including:

i) description in geographic coordinates (adopting SIRGAS2000 datum), of the area requested and its blueprint situation, where there should not have a previous request, due to the priority right. For dimension stones, the requested area can be up to 1000 hectares;

ii) the emoluments and payment receipt;

iii) technical term of responsibility (ART); and

iv) prospecting and research execution project.

Once the request form is filled out, the applicant has a 30-day deadline to present it for ANM's protocol, together with the other documents mentioned before. 
The prospecting execution plan must contain at least the following content:

a) bibliographic review approaching geographic and infrastructure aspects, such as municipality, freeways, highways, secondary roads, market features of dimension stones, and mining historical data, if available. In this item the geological features which may indicate dimension stone occurrence in that area must be presented;

b) Material and methods that will be used during the plan execution, such as geological mapping, pick/bulk sampling, geophysical campaign, laboratory tests, drilling, evaluation of mineral resources/ reserves, economic studies and exploitation viability;

\subsection{The exploration permit (EP)}

Once the miner has gotten the EP, beyond the obligation to carry out all prospecting and research work to find an ore deposit, the EP owner is compelled to:

- pay the Annual Fee Occupation per Hectare (TAH);

- begin exploration up to 60 days after the EP publication in the official government journal called Diário Oficial da União (DOU);

- deliver the Final Exploration Report (RFP) by the end of the EP deadline.

The extension of the EP deadline, for the same duration it is admissible, as long as the application has been made 60 days in advance of the EP deadline, and which must contain:

1-prospecting work done up to now report, called Partial Exploration Report, with PER;

2-justification for additional time for the exploration work completion;

3 -payment of the respective emoluments.

Once the protocol of this request is done, it will be evaluated by ANM specialized staff, and then a decision will be made if the applicant lives up to the respite. In a positive response, ANM Regional Manager Dispatch will be published at DOU with data related to the respite granted. During validity, the TAH payment is still mandatory.

There are two special cases in which the EP despite is legally based:

i-due to lack of accordance with terrain owner, a situation in which all legal procedures must have been followed through and the documental proof should be presented at despite requirement;

ii-when the targeted area interferes c) Budget and investment estimates for the follow-through of steps mentioned above, as well as the execution schedule, which must predict the prospecting execution from 01 up 03 years long. For dimension stones, it is recommended a 2-year duration.

It is important for the applicant to keep in mind that once the prospecting request protocol at ANM has been made, the absence of any document above implies in dismissal of the request. The protocol act initiates the administrative proceeding, which was done through printed paper. However, is noteworthy to mention that, on 30 September, 2019, the ANM's digital protocol has been implemented. From that date forward, printed documents are not

with environmental conservancy zones (UC). In this context, the miner has to provide all documents to get the UC manager authorization for mining activity in that area and confirm to ANM that all related bureaucracy is being managed.

The Brazilian Mining Code (CM) presents a precise definition of mineral exploration which involves: detailed geological mapping, rock outcrop observations and their correlations, geophysical and geochemistry surveys, trenches openings for detailed mapping, drillings through ore deposits, systematic samplings, chemical and physical analyses, and ore processing tests for market or industrial purposes (article 14 of CM).

Da Matta et al. (2007) and Haldar (2018) consider that mineral prospecting and research should necessarily involve the following procedures:

1. Bibliographical studies: gathering data from regional geological and topographic maps, satellite images, characterization of the terrain occupation and relevant aspects of the local infrastructure;

2. Field investigation: to confirm data gathered in stage 1 , through geological, structural and topographic mapping, sampling, drilling, technological characterization, and processing tests;

3. Calculation of reserves: involves hill slope (massif rock) and/or boulder volume determination of mineral deposit targeted for mining. The field investigation will be indispensable for characterization of physical boundaries of the reserves, which must be represented in maps and cross-sections. It is noteworthy that, in the current Brazilian regulatory scenario, reserve delimita- accepted by ANM's protocol.

Once the proceeding begins, the requested area is inserted into the ANM geographical information system called SIGMINE, where the priority right can be verified. In case of two or more requests for the same area, the priority will be granted for the applicant with the oldest protocol register date, while the other two will be dismissed. After that, once verified that the requested area is free for mining activity, and the prospecting and research plan evaluated and approved by ANM, the applicant gets the Exploration Permit, which can last from 1 up to 3 years (for dimension stones, it is usually granted for 2 years). During the evaluation procedure, additional data may be required from the applicant.

tion is the core of the mining permitting procedure. Then no compliance related to it, as well as reserve misrepresentation in maps and cross-sections can cause serious damage to permitting the mining procedure or even may become a request denial by ANM.

4. Mining Pre-viability/economic evaluation: at this stage market studies, economic and financial analysis should be carried out to verify if the mining of this reserve is possible and can generate profit. It should be demonstrated through simplified cash flow or/and other financial indicators. This statement should include the estimation costs of equipment acquisition, labor, supplies, support betterment to the mine operation, depreciation, amortization, tax payments including Mining Exploration Financial Compensation (CFEM).

5. RFP submitting: it's mainly a technical document that must contain the description of all mineral prospecting and researching done through EP validity. The Brazilian Mining Code says that the mineral prospecting and research must be part of geological, technological, qualitative and quantitative studies of the ore deposit target, as well as the mining feasibility from the technical and economic point of view. All this work has to be done by a qualified and legally authorized professional.

This being said, RFP may present only the three following conclusions:

1. the mining of the ore deposit is feasible technically and economically;

2. the prospected area has no ore deposit. In the present context, the dimension stone ore deposit was not discovered; 
3. in the prospected area, there is a dimension stone deposit, nevertheless, the mining feasibility and viability were not demonstrated, at least at the present moment, due to mineral processing, market, environmental, social, governmental, legal, infrastructural/logistical or economic reasons (CBRR, 2016).

Through technical evaluation of the RFP, ANM's technical staff will decide by:

- RFP approval: if it reveals the ore deposit at that local and it was character- ized as a mineral reserve;

- RFP approval denied: when presented with lack of proper technical instruction, or prospecting and researching work done was insufficient for the ore deposit discovery. In other words, no compliance was identified in RFP;

- RFP decision postponement: when it reveals the ore deposit at that location, however, the mining viability was not proven for short term, usually due to low ore quotation.

- RFP filing: when at that area was not discovered any ore deposit. This is the case where the area will be immediately available for a new EPR.

It's noteworthy that the last federal mining law modification permitted for additional mineral prospecting and research after RFP delivering to ANM. However, the data acquired cannot be used to modify the RFP. Such aspect of the mining law awaits complementary regulation.

ANM's regional manager. Unlike MPs, the GUs set a maximum of ore tonnage (t) production based on the type and usage ore; for silicate rocks, as dimension stones, it is fixed at $16.000 t$ per year, if marble, $10.000 t$ per year.

Unlike MP, the GU has a timespan, thereby the Decree $9406 / 2018$, the new Mining Code Regulation (MCR) establishes that GUs can be granted considering from 1 up to 3 years timespan and an extension will be allowed only once for the same period of time authorized before.

According to mining legislation standing, when this article was written, there are two aspects that deserve highlighting:

- If the decision related do RFP was postponed, then the GU granting procedure will depend on enforcement activity by ANM's technical staff, and if the aim for $\mathrm{GU}$ acquisition is for economic viability studies or industrial tests;

- if the RFP approval is denied or $\mathrm{EP}$ extension request is rejected, then the GU eventually granted will be automatically canceled.

mining plan, environment impact control plan, rescue and salvation plan, closing mine plan, risk management plan, Labor Health and Medical Control Plan and technical and economic viability studies.

It is important to keep in mind that ore deposit assessment involves several aspects, such as mine duration, investments, revenues, operational costs, taxes, working capital estimation, pay-back period, internal rate return, net present value, profitability, etc. All that cause effects on the socio-economic development of the mining activity target (Castro, 1997; Vidal et al.,2014; Almeida, 2017), hence ANM's staff have to take into account such information at ER and other requirement analyses. If economic viability is 
proven, in the following step the mining right owner will be summoned to deliver to ANM the Environment Installation License (IL) issued by the environmental agency. Like the other stages mentioned

\subsection{Mining Permit}

As said earlier, this is the main mining authorization according to Brazilian mining law, it does not have a timespan. To get the full-scale quarrying started, the miner must priorly acquire the Environmental Operation License, issued by the environment

\subsection{Licensing Regime}

Due to its simplicity, the administrative procedure in the ANM takes place faster than the MP granting procedure. Like the other regimes, the priority right is applied. In order to get a License Record Authorization ARL (equivalent to Mining Permit in authorization regime), the applicant must present to ANM: i) municipality authorization, ii) agreement signed by landowners or ownership declaration, if the applicant is the sole landowner, iii) description in geographic coordi- before, the applicant is allowed to complement his projects if ANM's staff judges are needed. Once this demand is satisfied by the applicant, the mining file folder will be sent to ANM's headquarters where the

agency. Once the MP has been granted, there is the on-site demarcation out of MP boundaries, whose detailed procedures will not be discussed in this article. Another noteworthy aspect is the fact that during all mining activities the miner has to obey the Regulat-

nates (adopting SIRGAS2000 datum) of the area requested and its blueprint situation, iii) the emoluments and payoff receipt; iv) ART for the documents pointed out in 'ii'. If the quarry involves blasting or mineral processing, a PAE is required and the ART related to it. Once the request is done, the applicant has 60 days to present to ANM the environmental license, which can be the installation or operation type. Figure 1 b) shows a simplified flowchart for the ARL granting procedure. decision about Mining Permission will be made (in case of minerals outside of the Law 6567/78 range the Mining Permission will be granted by the Energy and Mines Ministry (MME).

ing Mining Norms issued as DNPM Normative Act $n^{\circ} 237 / 2001$, as well as deliver the Annual Mining Report where all mining production must be claimed. Figure 1 a) shows a simplified flowchart of the current Brazilian mining permitting procedure.

Santos and Nascimento (2020) argue the need for municipality authorization as a drawback related to this regime. Thus, for any reason, that authorization expires or gets revoked, the ANM will have to revoke the ARL. Furthermore, an exploitation of a dimension stone deposit without enough information on its geological features and exploration data might lead to predatory mining activity. So far that has not happened, but it may in a short term.

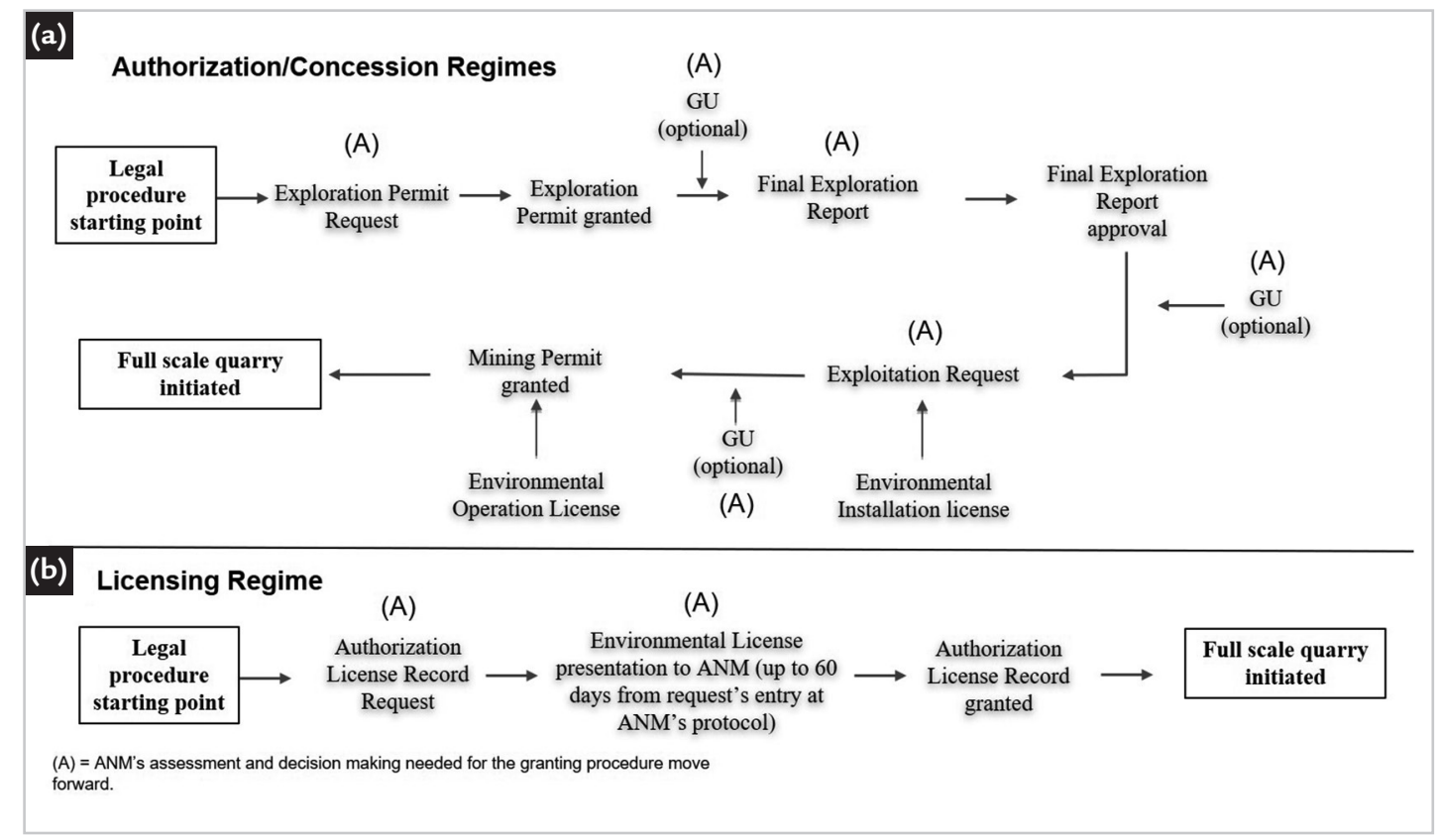

Figure 1 - Simplified flowchart of mining permitting procedure of Authorization/Concession and Licensing regimes according to Brazilian federal laws and complementary normative acts. It is important to keep in mind that interruption or dismissal in any of the steps mentioned above may prejudice the granting procedure.

\section{Results and discussions}

It is evident that GU has lost its real purposes mentioned earlier (item 3.3). This authorization, in many cases, is requested by dimension stone miners to anticipate their mineral exploitation.
Anyway, the miner should be aware that $\mathrm{GU}$ is considered a fragile mining permission, which limits the ore amount production, as well as, its timespan, which may be shorter than miner has intended. Therefore, it is not suitable for full-scale quarry.

In addition, and oddly enough, it is not uncommon to see the exploitation of dimension stones operating 
outside of physical limits of mineral reserves sketched in the RFP. This issue can seriously damage the miner, since that kind of situation, when it is taking place, the quarry operation must be interdicted by ANM according to DNPM normative act 155/2016. All that matter has its roots in the failure during the prospecting and reserves evaluation work, and the technical documents discussed earlier were drafted with lack of proper instruction.

Another critical point is the dimension stone attractiveness, which is quite volatile and currently faces strong competition with artificial products like compact stone marble, porcelain tile, which can reduce the dimension stone's market share (Chiodi Filho, 2018). Then a texture trait or color type currently sought after, a few years from now, that same rock type could become worthless. By that means, the professional conducting the prospecting and reserve assessment must be knowledgeable of market demands and its trends to avoid errors like mentioned here, which are not commonly observed in metal mining. Notwithstanding, the technical dossier delivered to ANM must be made considering all aspects mentioned in this article.

The government amendment of Law $6567 / 78$ was an attempt to facilitate access to mining permits in the dimension stones segment. No doubt, simplification of mineral exploration procedures along with guidance and technical training policies in favor of miners would constitute a better governmental measure following a rational usage of the Brazilian mineral resources. Thus, due to recent changes in Feederal mining legislation, we summarize some aspects of the current mining regimes available for dimension stone market (Tables 1 e 2).

Table 1 - Comparative analysis of mining regimes which dimension stone miners can access.

\begin{tabular}{c|c|c}
\hline \multicolumn{2}{c}{ Regimes availables for dimension stone mining in Brazil } \\
\hline ANM procedures & Authorization/Concession & Licensing \\
\hline Area extension consented & tardy & 50 ha \\
\hline Mineral exploration & 1000 ha & dispensable \\
\hline Municipality authorization & compulsory & compulsory \\
\hline Environmental licensing & dispensable & compulsory \\
\hline
\end{tabular}

Table 2 - Comparative analysis of mining permits that can be attained by dimension stone miners in Brazilian territory. MP = Mining Permit, GU = Exploitation Provisory Authorization, ARL = License Record Authorization.

\begin{tabular}{|c|c|c|c|}
\hline \multicolumn{4}{|c|}{ Mining Authorizations in Brazilian Legislation Applicable to Dimension Stone Sector } \\
\hline & \multicolumn{2}{|c|}{ Authorization/Concession } & \multirow{2}{*}{$\frac{\text { Licensing }}{\text { ARL }}$} \\
\hline & MP & GU & \\
\hline ANM procedures & tardy & moderadely prompt & prompt \\
\hline Duration & unlimited & 1 up 3 years & $\begin{array}{l}\text { it will be the expiration date of the agreement } \\
\text { landowner or municipality authorization, } \\
\text { chosen by the shortest expiration criteria. }\end{array}$ \\
\hline Legal safety & high & low & moderate \\
\hline Extention & not applicable & applicable only once & $\begin{array}{l}\text { applicable as many times required } \\
\text { (if fulfilled the legal requirements) }\end{array}$ \\
\hline Granting decision & ANM Headquarters & ANM regional units & ANM regional units \\
\hline
\end{tabular}

\section{Conclusions}

Based on all descriptions above, it becomes crystal clear that nowadays the Brazilian mining legislation is far from attending the dimension stones miner's longings, since the current regulatory system does not take into account the distinctiveness of that market, which is indeed quite different from metal mining. Despite all challenges the segment has faced, Brazilian soil has a huge potential to build the dimension stone quarries.

Currently, a transition is taking place inside the federal entity in charge to regulate all mining activity in Brazilian territory, from a department type structure, DNPM, to Federal Regulatory Agency, ANM, which is a technical and political endeavor from government aiming for proper and efficient management of the mineral resources. Thus, the current moment is highly appropriate for a detailed review of the mining permit procedure by ANM and MME, where upon, it could become itself quicker, reducing unnecessary bureaucracy and providing legal safety in the mining scenario.

\section{Acknowledgments}

The authors gratefully thank engr. Gisele Duque Bernardes de Sousa for reviewing this manuscript. 


\section{References}

AGRA, R.; AZEVEDO, T.; TOMI, G. Desafios na legalização de empreendimentos de mineração de pequeno porte: exemplo prático de uma mina de pequeno porte. In: CONGRESSO BRASILEIRO DE CARVÃO MINERAL, 3. 2011, Gramado/RS. Anais [...]. [S. l.]: ABCM, 2011.

ALMEIDA, W. E. Uma análise da importância do plano de aproveitamento econômico no processo de tomada de decisão na mineração. 2017. 118 f. Dissertação (Mestrado em Engenharia Mineral) - Escola de Minas, Universidade Federal de Ouro Preto, Ouro Preto, 2017.

BRASIL. Decreto Lei n ${ }^{\circ}$ 227, de 28 de fevereiro de 1967. Dá nova redação ao Decreto Lei no 1.985, de 29 de janeiro de 1940 (Código de Minas). Diário Oficial da União: seção 1, Brasília, DF, p. 2417, 28 fev. 1967.

BRASIL. Ministério de Minas e Energia. Departamento Nacional de Produção Mineral. Portaria nº 155 de 12/05/2016. Diário Oficial da União: seção 1, Brasília, DF, p. 32, 17 maio 2016.

BRASIL. Ministério de Minas e Energia. Agência Nacional de Mineração. Resolução n³7 de 04/06/2020. Diário Oficial da União: seção 1, Brasília, DF, p. 35, 8 jun. 2020.

CASTRO, M. C. G. Projeto para mineração de pequeno e médio porte. 1997. 151 f. Dissertação (Mestrado em Geociências) - Instituto de Geociências, Universidade Estadual de Campinas - UNICAMP, Campinas, 1997.

CHIODI FILHO, C. O setor brasileiro de rochas ornamentais. Brasília: ABIROCHAS, 2018. 34p. Available at: http://abirochas.com.br/wp-content/uploads/2018/06/abinoticias/Setor_de_Rochas_Ornamentais.pdf. Accessed: 06 Aug. 2019.

COMISSÃO BRASILEIRA DE RECURSOS E RESERVAS. Guia para declaração de resultados de exploração, recursos e reservas minerais. Edição 2016. Brasília: CBRR, 2016. p. 54. Available at: http://www.cbrr.org.br/docs/ guia_declaracao.pdf. Accessed: 06 Aug. 2019.

HALDAR, S. K. Mineral exploration: principles and applications. 2nd. ed. Indian Institute of Technology, Kharagpur, India: Elsevier, 2018. 378 p. Available at: https://doi.org/10.1016/B978-0-12-814022-2.00001-0. Accessed: 6 Aug. 2019.

SANTOS, Y. C. S.; NASCIMENTO, W. A. N. Projetos técnicos da mineração. In: SION, A. O. (org). Direito minerário em foco. Belo Horizonte: Editora DelRey, 2020. p.185-199.

VIDAL, F. W. H.; CASTRO, N. F.; AZEVEDO, H. C. A. (ed.). Tecnologia de rochas ornamentais: pesquisa, lavra e beneficiamento. Rio de Janeiro: CETEM, 2013. 700 p.

Received: 14 October 2019 - Accepted: 16 November 2020.

All content of the journal, except where identified, is licensed under a Creative Commons attribution-type BY. 